\title{
Efeito do fogo na vegetação espontânea em sistema agroflorestal, Pará, Brasil
}

\author{
Effect of fire in weeds of agroforestry system, Pará, Brazil

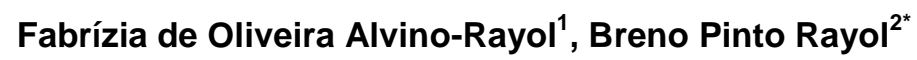 \\ ${ }^{1}$ Instituto Federal de Educação, Ciência e Tecnologia do Pará, Belém, Pará, Brasil. \\ ${ }^{2}$ Universidade Federal Rural da Amazônia, Belém, Pará. Brasil. *Autor para correspondência: bprayol@yahoo.com.br.
}

Submissão: 17/07/2018 / Aceite: 10/12/2019

\begin{abstract}
RESUMO
O objetivo deste trabalho foi avaliar o efeito do fogo na estrutura, composição florística e diversidade da vegetação espontânea em um sistema agroflorestal com dois tipos de preparo da área: com e sem queima. O sistema agroflorestal foi composto pelas espécies: paricá (Schizolobium amazonicum), açaí (Euterpe oleracea) e cupuaçu (Theobroma grandiflorum). Para a amostragem da flora da vegetação espontânea, utilizou-se um gabarito de madeira de $0,25 \mathrm{~m}^{2}$, lançado, aleatoriamente, 20 vezes em cada área avaliada. Foram calculadas a diversidade de espécies (Índice de diversidade de Shannon) e taxa de cobertura da vegetação espontânea. As espécies inventariadas foram coletadas e enviadas para identificação nos herbários da região. A diversidade de espécies não diferiu estatisticamente nos dois tratamentos. Porém, a maior taxa de cobertura de vegetação espontânea foi observada na área preparada com o uso do fogo. A composição florística da vegetação espontânea apresentou somente $32,3 \%$ de similaridade entre as duas áreas. A espécie que apresentou maior importância na flora emergente em ambas as áreas foi Myrciaria tenella (DC.) O. Berg. O fogo influenciou na composição florística e na taxa de cobertura da vegetação espontânea nas áreas avaliadas.
\end{abstract}

PALAVRAS-CHAVE: queima controlada, agricultura familiar, Amazônia.

\begin{abstract}
The objective of this study was to assess the effect of fire on the structure, floristic composition, and diversity of weeds in an agroforestry system with two types of preparation of the area: with and without burning. The agroforestry system was composed of the species: Schizolobium amazonicum, Euterpe oleracea, and Theobroma grandiflorum. For the sampling of the vegetation of the weeds, a wooden template of $0.25 \mathrm{~m}^{2}$ was used, randomly launched 20 times in each area assessed. The diversity of species (Shannon Diversity Index) and vegetation cover rate were calculated. The inventoried species were collected and sent for identification in the herbariums of the region. The diversity of species did not differ statistically in the two treatments. However, the highest rate of spontaneous vegetation cover was observed in the area prepared with the use of fire. The floristic composition of the spontaneous vegetation presented only $32.3 \%$ of similarity between the two areas. The species that showed major importance in the emergent flora in both areas was Myrciaria tenella. Fire influenced the floristic composition and vegetation cover rate in the assessed areas.
\end{abstract}

KEYWORDS: controlled burning, family farming, Amazon.

\section{INTRODUÇÃO}

Os sistemas agrícolas desenvolvidos nos trópicos, comumente, têm apresentado problemas de estabelecimento do plantio e de baixa produtividade, causados pela interferência da vegetação espontânea, comprometendo o equilíbrio dos fatores de produção, por competir com estes para o seu crescimento (SOUZA et al. 2003). Entende-se por vegetação espontânea o conjunto de espécies vegetais que se desenvolvem sem cultivo e sem intervenção humana (SCHNEIDER 2007).

Dentre os modelos de produção agrícola destacam-se os sistemas agroflorestais, caracterizados pelo cultivo simultâneo ou escalonado, no espaço e no tempo, de árvores com espécies agrícolas anuais, plurianuais ou perenes, na presença ou não de animais (NAIR 2007). Esses sistemas também têm apresentado problemas de estabelecimento na fase inicial do plantio e baixa produtividade, causados pela Rev. Ciênc. Agrovet., Lages, SC, Brasil (ISSN 2238-1171) 
interferência das plantas espontâneas, constituindo um dos mais sérios problemas enfrentados pelos produtores. Este tipo de interferência depende de fatores ligados à cultura (espécie, espaçamento e densidade de plantio), à comunidade infestante (composição específica, densidade e distribuição) e à época e extensão do período de convívio (BRIGHENTI \& OLIVEIRA 2011). Outro efeito negativo da vegetação espontânea em cultivos está associado à ação indireta, quando essas plantas hospedam microrganismos patogênicos para a cultura (MILEO et al. 2006). A vegetação espontânea que ocupa extensas áreas tornase potencial fonte de inóculo de fitopatógenos em cultivos comerciais, desempenhando papel fundamental na epidemiologia das doenças como hospedeiras secundárias (CHAVES et al. 2003).

A análise estrutural da vegetação espontânea de um determinado cultivo é muito importante para que se possam ter parâmetros confiáveis acerca da florística das plantas de um determinado nicho (OLIVEIRA \& FREITAS 2008). Neste sentido, os índices fitossociológicos são de grande importância para avaliar os impactos que sistemas de manejo ou as práticas agrícolas exercem sobre a dinâmica de crescimento e ocupação de comunidades infestantes em agroecossistemas. A caracterização das comunidades de vegetação espontânea contribui na detecção de problemas e na escolha de estratégias de manejo e de controle a serem empregadas nos sistemas agrícolas (YANAGIZAWA \& MAIMONI-RODELLA 1999)

Os efeitos diferenciados dos sistemas de preparo do solo sobre as plantas invasoras podem modificar a composição botânica da comunidade (DUARTE \& DEUBER 1999, PEREIRA et al. 2000). A queima da vegetação, por exemplo, afeta diretamente o crescimento, a sobrevivência e reprodução das plantas e ainda atua sobre a dinâmica do banco de sementes. É um dos poucos distúrbios que dizima plantas adultas, contribuindo com acentuadas mudanças na composição florística de estruturas vegetacionais (STEUTER \& McPHERSON 1995, BOND \& VAN WILGEN 1996).

O estudo das comunidades colonizadoras iniciais de áreas onde a vegetação foi destruída pelo fogo é de grande relevância, por auxiliar nos programas de seleção e manejo de espécies (MARTINS et al. 2002). A falta de informações sobre o controle da vegetação espontânea em áreas de sistemas agroflorestais, aliada a escassez de estudos sobre a influência do fogo neste tipo de vegetação são fatores limitantes nos sistemas de cultivo alternativos que promovem a sustentabilidade das atividades e aumentam a qualidade de vida do produtor e de sua família. Com base nesse contexto, o presente estudo teve como objetivo avaliar o efeito do fogo na estrutura, composição florística e diversidade da vegetação espontânea em um sistema agroflorestal com dois tipos de preparo da área.

\section{MATERIAL E MÉTODOS}

O presente estudo foi desenvolvido na Comunidade Benjamim Constant, a $28 \mathrm{~km}$ da sede do município de Bragança, nordeste do estado do Pará, em propriedade agrícola de produtor familiar, localizada nas coordenadas geográficas $-01^{\circ} 11^{\prime} 2,9$ " S e $-46^{\circ}=40^{\prime} 10,80$ " W. A cobertura vegetal predominante na área é vegetação secundária em diversos estágios sucessionais, oriunda da agricultura de corte-e-queima. O clima da região, pela classificação de Köppen, é do tipo Am, com precipitação pluviométrica anual de 1750 a $2500 \mathrm{~mm}$. Os solos são quimicamente pobres e muito intemperizados (ANDRADE et al. 2017).

O delineamento experimental utilizado foi o inteiramente casualizado. A área experimental constituída de $9.504 \mathrm{~m}^{2}$, dividida em dois tratamentos (com queima e sem queima). O preparo da área com o uso do fogo foi realizado pela supressão da vegetação secundária, seguida da queima do material vegetal seco 50 dias após o corte. O material residual proveniente da queima foi retirado da área. $\mathrm{Na}$ área onde não foi realizada a queima, o preparo se deu pela capina e desbastes seletivos da vegetação secundária de aproximadamente 10 anos de sucessão, processo conhecido regionalmente como bosqueamento, o que permitiu a permanência de alguns indivíduos de espécies arbóreas. O sistema agroflorestal foi composto pelas espécies: paricá (Schizolobium amazonicum Huber ex Ducke), açaí (Euterpe oleracea Mart.) e cupuaçu (Theobroma grandiflorum (Willd. ex Spreng.) K. Schum.). Os espaçamentos utilizados foram: $3 \times 3$ m (para o paricá e açaí) e $9 \times 9 \mathrm{~m}$ (cupuaçu).

A amostragem da vegetação espontânea foi realizada 90 dias após o preparo da área, por meio do método de parcelas (BRAUN-BLANQUET 1979), utilizando-se um gabarito de madeira de $0,50 \mathrm{~m} \times 0,50 \mathrm{~m}$ o qual foi lançado ao acaso, 20 vezes em cada área, perfazendo um total de $5,0 \mathrm{~m}^{2}$. As plantas foram cortadas rente ao solo, contadas e separadas, sendo preparadas, ainda no campo, exsicatas de todas as espécies encontradas. O material coletado foi levado ao Herbário do Museu Paraense Emílio Goeldi MPEG para a identificação. As amostras de material botânico não identificadas receberam códigos de morfotipo (material não identificado taxonomicamente) e foram consideradas como espécies diferentes entre $\mathrm{si}$, mesmo quando pertencentes ao mesmo gênero. Os nomes científicos das espécies com os respectivos 
autores foram confirmados e atualizados por meio da página da WEB do Missouri Botanical Garden (http://mobot.bobot.org/W3T/Search/vas.html).

A composição florística foi analisada através da riqueza (número de espécies encontradas na área de estudo) e a distribuição dessas espécies nas suas respectivas famílias botânicas. As espécies identificadas também foram classificadas de acordo com as seguintes categorias: árvore, arbustos, ervas e lianas. Foi considerada vegetação espontânea todas as plantas que se encontravam nas parcelas e que não foram cultivadas. Aos 30, 60, 90 e 120 dias após a queima foi estimada ao acaso em cada parcela a porcentagem de cobertura vegetal de cada espécie de leguminosas de cobertura, e de solo exposto.

Para o cálculo da porcentagem de cobertura da vegetação espontânea utilizou-se a seguinte fórmula: $\mathrm{C} \%=100 \%-\mathrm{SE} \%-\mathrm{LC} \%$, em que: $\mathrm{C} \%=$ Porcentagem de cobertura da vegetação espontânea em cada parcela; $\mathrm{SE} \%=$ Porcentagem de solo exposto em cada parcela; $\mathrm{LC} \%=$ Porcentagem de espécies de interesse. A diversidade de espécies foi calculada através do índice de diversidade de Shannon $\left(\mathrm{H}^{\prime}\right)$ (MAGURRAN 1988), calculado conforme BROWER et al. (1990). A estrutura horizontal da área experimental foi avaliada através dos seguintes parâmetros: densidade relativa, frequência relativa, dominância relativa e Índice de Valor de Importância da vegetação espontânea conforme proposto por MULLER-DOMBOIS \& ELLENBERG (1974). A similaridade florística da vegetação espontânea entre as duas áreas foi comparada a partir do índice de Similaridade de Sorensen (MUELLER-DOMBOIS \& ELLENBERG 1974).

Os valores médios da porcentagem de cobertura da vegetação espontânea e do índice de diversidade de Shannon foram utilizados para a comparação entre as duas áreas, por meio do meio do teste de Student (t) a 5\% de probabilidade. Para tanto, utilizou-se o programa Bio Estat 5.0 (AYRES et al. 2007).

\section{RESULTADOS}

O inventário da composição florística realizado nas duas áreas revelou a ocorrência de plantas pertencentes a 25 famílias, 44 gêneros e 52 espécies identificadas e quatro sem identificação. As famílias que mais se destacaram na vegetação espontânea das áreas avaliadas foram Fabaceae com sete espécies, seguida de Cyperaceae, Dilleniaceae e Myrtaceae com quatro espécies cada. $\mathrm{Na}$ área com queima foram registradas 28 espécies distribuídas em 17 famílias e na sem queima 32 espécies em 18 famílias.

Os dados referentes à cobertura e diversidade da vegetação espontânea nas duas áreas são apresentados na Tabela 1. A área que foi preparada com o uso do fogo apresentou maior percentual de cobertura de vegetação espontânea que a área onde não se usou a queima. Em termos de diversidade de espécies, não houve diferença significativa entre os dois tratamentos.

Tabela 1. Percentual de cobertura e diversidade de vegetação espontânea em sistema agroflorestal submetido a dois tipos de preparo de área (tratamentos).

Table 1. Percentage of coverage and diversity of weeds in the agroforestry system submitted to two types of area preparation (treatments).

\begin{tabular}{cll}
\hline Tratamento & Cobertura $(\%)$ & Diversidade \\
\hline Com queima & $83,95 \mathrm{a}$ & $1,36 \mathrm{a}$ \\
Sem queima & $78,37 \mathrm{~b}$ & $1,32 \mathrm{a}$ \\
\hline
\end{tabular}

Médias seguidas pela mesma letra, não diferem pelo teste de Student (t) a $5 \%$ de probabilidade.

As duas áreas apresentaram variação quanto à composição florística da vegetação espontânea, com somente $32,8 \%$ de similaridade florística, segundo o índice de Sorensen. Este valor pode ser considerado baixo se for levado em consideração que as áreas em questão são compostas pelas mesmas espécies e arranjos espaciais, além de estarem localizadas na mesma propriedade familiar e circundadas pelo mesmo tipo de vegetação (secundária).

$\mathrm{Na}$ área preparada com o uso do fogo houve predomínio de lianas e espécies herbáceas, enquanto que na área sem queima foram as arbóreas (Figura 1). Na área preparada com fogo, Myrciaria tenella apresentou maior valor de IVI em razão dos altos valores de densidade, frequência e dominância. Outra espécie que merece destaque é Cyperus laxus. A abundância, frequência e dominância desta espécie aumentaram neste sistema agroflorestal. A importância destas espécies Urena lobata e Urena sp., ambas pertencentes a família Malvaceae, também se destacaram, apresentando altos valores de densidade e dominância. As espécies mais frequentes foram Myrciaria tenella, distribuída em 8,82\% da área, e Cyperus laxus como a segunda espécie mais frequente (6,86\%). Porophyllum ruderale, da família Asteraceae, 
também merece destaque, ocupando a quarta colocação em ordem de importância (Tabela 2).

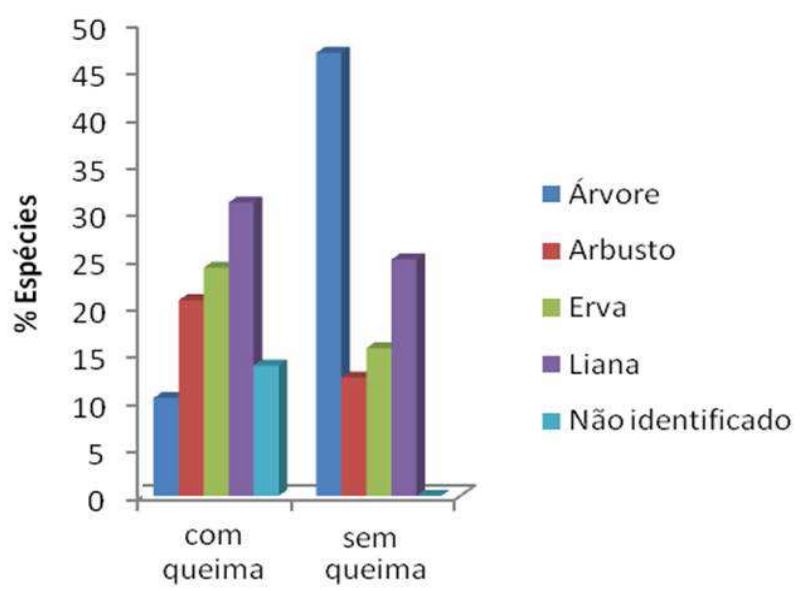

Figura 1. Percentual de espécies por forma de vida da vegetação espontânea em sistema agroflorestal submetido a dois tipos de preparo de área (tratamentos).

Figure 1. Percentage of species by life form of weeds in the agroforestry systems submitted to two types of area preparation (treatments).

Tabela 2. Percentual dos parâmetros fitossociológicos apresentado pelas espécies de vegetação espontânea na área preparada com uso de fogo (DR: densidade relativa; FR: frequência relativa, DoR: dominância relativa; IVI: Índice de Valor de Importância).

Table 2. Percentage of phytosociological parameters of weed species in the area prepared using fire (DR: Relative Density; FR: Relative Frequency; Dom R: Relative Dominance; IVI: Importance Value Index Modified).

\begin{tabular}{llllc}
\hline Espécie & DR & FR & DoR & IVI \\
\hline Myrciaria tenella (DC.) O. Berg. & 8,80 & 8,82 & 8,93 & 26,55 \\
Cyperus laxus Lam. & 8,21 & 6,86 & 8,44 & 23,51 \\
Urena lobata L. & 7,04 & 5,88 & 5,96 & 18,88 \\
Porophyllum ruderale (Jacq.) Cass. & 6,45 & 4,90 & 6,95 & 18,30 \\
Urena sp. & 5,87 & 5,88 & 5,46 & 17,21 \\
Bauhinia macrostachya Benth. & 5,28 & 4,90 & 4,71 & 14,90 \\
Talisia carinata Radlk. & 5,57 & 3,92 & 4,96 & 14,46 \\
Byrsonima aerugo Sagot. & 4,11 & 5,88 & 4,47 & 14,45 \\
Davilla aspera (Aubl.) & 5,57 & 3,92 & 4,22 & 13,71 \\
Scoparia dulcis L. & 3,23 & 4,90 & 4,47 & 12,59 \\
Smilax schomburgkiana Kunth & 3,81 & 3,92 & 4,22 & 11,95 \\
Rhynchanthera hispida Naudin & 3,81 & 3,92 & 3,97 & 11,70 \\
Sabicea amazonensis Wernham & 3,81 & 3,92 & 3,72 & 11,46 \\
Solanum asperum L. & 3,23 & 2,94 & 3,23 & 9,39 \\
Passiflora nítida Kunth & 2,35 & 3,92 & 2,73 & 9,00 \\
Mimosa annularis Spruce ex Benth. & 2,93 & 2,94 & 2,73 & 8,60 \\
Uncaria guianensis (Aubl.) J.F. Gmel. & 2,64 & 2,94 & 2,98 & 8,56 \\
Coutoubea spicata Aubl. & 2,93 & 2,94 & 2,48 & 8,36 \\
Doliocarpus brevipedicellatus Garcke & 2,35 & 2,94 & 2,23 & 7,52 \\
Ravenala guyannensis (Rich.) Steud. & 1,76 & 2,94 & 2,48 & 7,18 \\
Scleria pterota (Rchb. ex Schltdl. e Cham.) & 2,35 & 1,96 & 2,23 & 6,54 \\
Pilocarpus sp. & 2,05 & 1,96 & 1,74 & 5,75 \\
Serjania paucidentata DC. & 1,47 & 0,98 & 1,24 & 3,69 \\
Continua... & & & & \\
Cian & & &
\end{tabular}




\section{Continuação da tabela 2}

\begin{tabular}{lllll} 
Morfotipo 1 & 0,88 & 0,98 & 1,24 & 3,10 \\
Morfotipo 2 & 0,88 & 0,98 & 0,99 & 2,85 \\
Passiflora sp. & 0,88 & 0,98 & 0,74 & 2,60 \\
Morfotipo 3 & 0,59 & 0,98 & 0,99 & 2,56 \\
Inga falcistipula Ducke & 0,59 & 0,98 & 0,74 & 2,31 \\
Morfotipo 4 & 0,59 & 0,98 & 0,74 & 2,31 \\
\hline Total geral & 100 & 100 & 100 & 300 \\
\hline
\end{tabular}

$\mathrm{Na}$ área sem queima, Myrciaria tenella também se destacou, apresentando o maior valor IVI, ocupando tal posição especialmente por sua alta dominância. Os valores de dominância relativa mais representativos na área sem queima foram evidenciados para Myrciaria tenella e Davilla rugosa. Somadas as dominâncias destas espécies chega-se a 17,72\% (Tabela 3).

Tabela 3. Percentual dos parâmetros fitossociológicos apresentado pelas espécies de vegetação espontânea na área sem queima (DR: densidade relativa; FR: frequência relativa; DoR: dominância relativa; IVI: Índice de Valor de Importância).

Table 3. Percentage of phytosociological parameters of weed species in the area prepared without using fire (DR-Relative Density; FR-Relative Frequency; Dom R: Relative Dominance; IVI: Importance Value Index Modified).

\begin{tabular}{|c|c|c|c|c|}
\hline Espécie & DR & $\mathrm{FR}$ & DoR & IVI \\
\hline Myrciaria tenella (DC.)O.Berg. & 11,36 & 8,44 & 11,23 & 31,04 \\
\hline Davilla rugosa Poir. & 7,80 & 6,22 & 6,49 & 20,50 \\
\hline Inga alba Wild. & 6,01 & 6,22 & 6,33 & 18,56 \\
\hline Croton matourensis Aubl. & 6,01 & 6,22 & 6,17 & 18,41 \\
\hline Spermacoce verticillata (L.) G. Mey. & 5,79 & 5,33 & 6,33 & 17,45 \\
\hline Connarus sp. & 5,57 & 5,78 & 5,54 & 16,88 \\
\hline Arrabidaea bilabiata (Sprague) Sandwith & 5,35 & 5,78 & 5,38 & 16,50 \\
\hline Tabernaemontana angulata Mart. & 4,68 & 5,33 & 5,22 & 15,23 \\
\hline Galipea trifoliata Aubl. & 4,68 & 4,00 & 4,27 & 12,95 \\
\hline Attalea maripa (Aubl.) Mart. & 3,12 & 4,44 & 3,64 & 11,20 \\
\hline Clidemia hirta (L.) D. Don & 3,34 & 4,00 & 3,16 & 10,51 \\
\hline Scleria pterota (Rchb. ex Schltdl. e Cham.) & 3,79 & 3,11 & 3,48 & 10,38 \\
\hline Memora allamandiflora Bureau ex K. Schum. & 3,34 & 3,56 & 3,48 & 10,38 \\
\hline Phenakospermum guianensis Aubl. & 3,12 & 3,11 & 2,85 & 9,08 \\
\hline Lasiacis ligulata Hitchc. e Chase & 2,90 & 3,11 & 2,85 & 8,85 \\
\hline Senna latifolia (G. Mey.) H.S. Irwin e Barneby & 2,67 & 2,22 & 2,37 & 7,27 \\
\hline Mabea angustifólia Spruce ex Benth. & 1,78 & 2,67 & 2,06 & 6,51 \\
\hline Myrcia fallax (Rich.) DC. & 2,23 & 1,78 & 1,74 & 5,75 \\
\hline Rhynchospora rubber Vahl & 1,78 & 1,78 & 2,06 & 5,62 \\
\hline Mandevilla sp. & 1,78 & 1,78 & 1,90 & 5,46 \\
\hline Paulinia sp. & 1,78 & 1,78 & 1,74 & 5,30 \\
\hline Davila sp. & 1,56 & 1,78 & 1,74 & 5,08 \\
\hline Dalbergia sp. & 1,56 & 1,78 & 1,42 & 4,76 \\
\hline Davilla aspera (Aubl.) & 1,34 & 1,78 & 1,27 & 4,38 \\
\hline Myrcia cuprea (O. Berg) Kiaersk. & 1,34 & 1,33 & 1,58 & 4,25 \\
\hline Gustavia augusta L, & 1,11 & 1,33 & 1,11 & 3,55 \\
\hline Sabicea amazonensis Wernham & 1,11 & 1,33 & 1,11 & 3,55 \\
\hline Abarema cochleata (Willd.) Barneby e J.W. Grimes & 1,11 & 1,33 & 0,95 & 3,40 \\
\hline
\end{tabular}

Continua... 


\section{Continuação da tabela 3}

\begin{tabular}{lrrrr} 
Abarema cochleata (Willd.) Barneby e J.W. Grimes & 1,11 & 1,33 & 0,95 & 3,40 \\
Platonia insignis Mart. & 0,45 & 0,44 & 0,63 & 1,52 \\
Solanum sp. & 0,45 & 0,44 & 0,32 & 1,21 \\
Myrcia sp. & 0,22 & 0,44 & 0,32 & 0,98 \\
\hline Total geral & 100 & 100 & 100 & 300 \\
\hline
\end{tabular}

\section{DISCUSSÃO}

Os menores percentuais de cobertura da vegetação espontânea foram registrados no arranjo onde não houve o uso do fogo no preparo da área. Isto pode ter ocorrido devido ao acúmulo de resíduos, provenientes da vegetação espontânea anterior ao cultivo, que dificultou a taxa de germinação dos propágulos presentes no banco de sementes do solo e minimizou a proliferação de vegetação espontânea. CORREIA et al. (2006) também observaram que o efeito físico da cobertura morta dificulta o surgimento da vegetação espontânea. Já a área que sofreu ação do fogo, apresentou elevado percentual de cobertura de vegetação espontânea. Isso pode ser justificado pelo fato de que após a ocorrência do fogo, além da liberação de espaço, há grande entrada de nutrientes disponível no solo devido à queima de matéria orgânica (RHEINHEIMER et al. 2003, MARQUES et al. 2011), o que pode beneficiar as primeiras espécies que colonizam este ambiente.

$\mathrm{Na}$ área queimada as formas de vida predominantes foram as ervas e lianas. As comunidades dessas formas de vidas, quando muito agressivas, podem intensificar a competição por recursos e atrasar 0 processo de regeneração natural das espécies arbóreas (LEAL et al. 2006). Assim, a baixa representatividade das espécies arbóreas na vegetação espontânea da área preparada com o uso do fogo deve-se ao fato de que as suas plântulas oriundas de sementes e rebrotas tiveram que enfrentar o grande potencial competitivo das herbáceas e lianas. Além disso, a vegetação de porte arbustivo-arbóreo é significativamente reduzida após o fogo (SAMPAIO et al. 1993).

As lianas possuem espectro mais diversificado de adaptações para a reprodução vegetativa que as espécies arbóreas e têm grande capacidade de rebrota, garantindo rápida ocupação de áreas que sofreram distúrbios, além de serem, naturalmente, mais abundantes (JANZEN 1980, PUTZ 1984, GERWING 2003). As ervas e lianas tendem a ocupar o espaço deixado pelas espécies arbóreas e arbustivas queimadas, conforme observado também por UHL (1987), nos primeiros seis meses de sucessão pós fogo na Amazônia, por MELO \& DURIGAN (2010) em floresta estacional e por LEAL et al. (2006) em sistemas agrícolas de produção no nordeste paraense.

$\mathrm{Na}$ área onde não foi feito o uso do fogo no preparo do solo, as formas de vida mais comuns encontradas na vegetação espontânea amostrada foram arbórea e arbustiva. Estes resultados seguem a tendência apontada por outros estudos realizados em áreas que não sofreram queima, onde a forma de vida predominante foi a arbórea (MELO \& DURIGAN 2010).

Quanto à similaridade florística entre as áreas estudadas, observou-se uma baixa similaridade. Isso indica que o fogo alterou a composição da flora espontânea, contribuindo de maneira efetiva na dissimaliridade florística da vegetação espontânea entre os sistemas estudados. O impacto da queimada pode influenciar fortemente o processo de sucessão vegetal e consequentemente a futura composição da vegetação (SAMPAIO et al. 1993, LEAL et al. 2006). Desta forma, a diferença na composição das espécies da flora emergente entre as áreas avaliadas pode ser atribuída aos sistemas de manejo e preparo do solo realizados.

\section{CONCLUSÃO}

O fogo causou modificações na composição florística da vegetação espontânea nas áreas avaliadas. A área preparada com o uso do fogo apresentou maior suscetibilidade ao desenvolvimento e propagação da vegetação espontânea, sobretudo de espécies herbáceas e lianas.

Os resultados obtidos no presente trabalho são úteis nas escolhas de táticas de manejo de vegetação espontânea. Pesquisas adicionais são necessárias para melhorar o entendimento do efeito de uso do fogo em sistemas de produção familiar na Amazônia, e de como este interage com outros fatores econômicos e sociais de uso da terra.

\section{AGRADECIMENTOS}

Ao Conselho Nacional de Desenvolvimento Científico e Tecnológico (CNPq) por conceder a bolsa de 
doutorado para a primeira autora.

\section{REFERÊNCIAS}

ANDRADE VMS et al. 2017. Considerações sobre clima e aspectos edafoclimáticos da Mesorregião Nordeste Paraense. In: CORDEIRO IMCC et al. (Org.). Nordeste Paraense: panorama geral e uso sustentável das florestas secundárias. Belém: EDUFRA. p.59-96.

AYRES $M$ et al. 2007. BioEstat 5.0: Aplicações estatísticas nas áreas das ciências biológicas e médicas: Sociedade Civil Mamirauá/Belém. Brasília: CNPq. 290p.

BOND WJ \& VAN WILGEN BW. 1996. Fire and plants. London: Chapman e Hall. 263p. (Population and community biology 14).

BRAUN-BLANQUET J. 1979. Fitossociología: bases para el estudio de las comunidades vegetales. Madri: H. Blume. 820p.

BRIGHENTI AM \& OLIVEIRA MF. 2011. Biologia de plantas daninhas. In: OLIVEIRA JÚNIOR RS et al. (Eds). Plantas daninhas e seu manejo. Curitiba: Omnipax, p.1-37.

BROWER JE et al. 1990. Field and laboratory methods for general ecology. 3.ed. New York: WMC Brown Publisher. 237p.

CHAVES ALR et al. 2003. Erigon bonariensis: hospedeira alternativa do Lettuce mosaic vírus no Brasil. Fitopatologia Brasileira 28: 307-311.

CORREIA NM et al. 2006. Influência do tipo e da quantidade de resíduos vegetais na emergência de plantas daninhas. Planta daninha 24: 245-253.

DUARTE AP \& DEUBER R. 1999. Levantamento de plantas infestantes em lavouras de milho "safrinha" no Estado de São Paulo. Planta Daninha 17: 297-307.

GERWING J. 2003. A diversidade de histórias de vida natural entre seis espécies de cipós em floresta nativa na Amazônia Oriental. In: VIDAL E \& GERWING EJJ (Org.). Ecologia e manejo de cipós na Amazônia Oriental. Belém: Imazon. p.95-119.

JANZEN DH. 1980. Ecologia vegetal nos trópicos. São Paulo: EDUSP. 79p.

LEAL EC et al. 2006. Banco de sementes em sistemas de produção de agricultura com queima e sem queima no município de Marapanim, Pará. Boletim do Museu Paraense Emílio Goeldi Ciências Naturais 1: 19-29.

MAGURRAN AE. 1988. Ecological diversity and its measurement. Princeton: Princeton University Press. 177p.

MARTINS SV et al. 2002. Regeneração pós-fogo em um fragmento de Floresta Estacional Semidecidual no município de Viçosa, MG. Ciência Florestal 12: 11-19.

MARQUES LJP et al. 2011. Dinâmica de populações e fitossociologia de plantas daninhas no cultivo do feijão-caupi e mandioca no sistema corte e queima com o uso de arado. Planta Daninha 29: 981-989.

MELO ACG \& DURIGAN G. 2010. Impacto do fogo e da regeneração da comunidade vegetal em borda de Floresta Estacional Semidecidual (Gália, SP, Brasil). Revista Brasileira de Botânica 33: 37-50.

MILEO LJ et al. 2006. Plantas de cobertura de solo como hospedeiras alternativas de Colletotrichum guaranicola. Planta Daninha 24: 677-683.

MULLER-DOMBOIS D \& ELLENBERG H. 1974. Aims and methods of vegetation ecology. New York: Jhon Wiley e Sons. 574p.

NAIR PKR. 2007. The coming of age of agroforestry. Journal of the Science of Food and Agriculture 87: $1613-161$.

OLIVEIRA AR.\& FREITAS SP. 2008. Levantamento fitossociológico de plantas daninhas em áreas de produção de cana-de-açúcar. Planta Daninha 26: 33-46.

PEREIRA ES et al. 2000. Avaliações qualitativas e quantitativas de plantas daninhas na cultura da soja submetida aos sistemas de plantio direto e convencional. Planta Daninha 18: 207-217.

PUTZ FE. 1984. The natural history of lianas on Barro Colorado Island, Panamá. Ecology 65: 1713-1724.

RHEINHEIMER DS et al. 2003. Modificações nos atributos químicos de solo sob campo nativo submetido à queima. Ciência Rural 33: 49-55.

SAMPAIO EVSB et al. 1993. Effect of different fire severities on coppicing of caatinga vegetation in Serra Talhada, PE, Brazil. Biotropica 25: 452-460.

SCHNEIDER AA. 2007. A flora naturalizada no estado do Rio Grande do Sul, Brasil: herbáceas subespontâneas. Biociências 15: 257-268.

SOUZA LSA et al. 2003. Composição florística de plantas daninhas em agrossistemas de cupuaçuzeiro (Theobroma grandiflorum) e pupunheira (Bactris gasipaes). Planta Daninha 21: 249-255.

STEUTER AA \& McPHERSON GR. 1995. Fire as a physical stress. In: BEDUNAH DJ \& SOSEBEE RE. Wildland plantas physiological ecology and developmental morphology. Denver: Society for Range Management. p.550-579.

UHL C. 1987. Factors controlling succession following slashand-burn agriculture in Amazonia. The Journal of Ecology 75: 377-407.

YANAGIZAWA YANP \& MAIMONI-RODELLA RCS. 1999. Composição florística e estrutura da comunidade de plantas do estrato herbáceo em áreas de cultivo de árvores frutíferas. Planta Daninha 17: 459-468. 